human and civil rights. In that spirit, I respectfully request your personal attention to his welfare.

With great respect, I am

Sincerely yours,

Richard L. Sklar

President

In the Case of "Bantustans", (continued):

18 December, 1981

Dear Mr. Sklar:

We agree that only South Africa recognizes the "Homelands" as independent nations. Insofar as we can tell, no Defense Mapping Agency product depicts these "Homelands" as independent nations. However, the National Geographic Map titled "The Political World", dated 1980, shows the "Homelands" separately, but the map carries a note stating that only South Africa recognizes them as independent countries. It is possible that if one did not see the note, one might think the "homelands" were separate countries. Suggest you contact the national Geographic Society and discuss this with them.

At the present time, the Defense Mapping Agency requires and shows an international boundary between Morocco and Western Sahara on our maps. Prior to 1980 , however, Western Sahara was considered a dependent political entity and was not shown as an independent country. If you are looking at maps older than 1980 , you may very well see the Western Sahara portrayed as an integral part of Morocco. It should be noted that the National Geographic map titled "The Politcal World", 1980 shows both Morocco and Western Sahara in yellow tint with no international boundary between, thereby implying both countries are governed by Morocco. Again may we suggest you contact the National Geographic Society and discuss this with them.

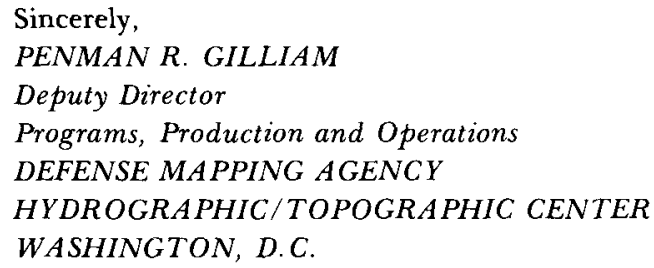

\title{
Re: ICA AND FULBRIGHT GRANTS FOR AFRICA
}

Dear Mr. Cosentino,

Thank you for your letter expressing your support for the International Communication Agency's (ICA) cultural and academic programs, including the Fulbright scholarship program.

I share your concern that the Reagan Administration's budget request for ICA's academic programs would cut these exchanges by more than $50 \%$. I have long supported these exchange programs as important vehicles to promote better understanding and to improve U.S. relations with foreign countries.

The Senate has proposed that the ICA exchange programs be allocated $\$ 101.6$ million. But final action on the State, Justice and Commerace Departments appropriations bill for FY ' 82 was not completed due to delay caused by debate on a school prayer amendment. Thus the programs will proceed under the continuing budget resolution at the FY ' 81 level of $\$ 100$ million. It is expected that the appropriations bill will come up 
early in 1982. You can count on me to join in efforts to provide adequate funding for the ICA's cultural and academic programs.

I appreciated having your input on this issue.

Sincerely,

Alan Cranston

United States Senate

\section{Annual Award for Life-Long Contribution to African Studies}

Dear Don,

Every year the Association honors the author of the most outstanding work on Africa in its Herskovits award. The award is prestigious and has gained in status over the years. I think however that an Association like our own, rapidly approaching its silver jubilee in 1982, should institute an even more prestigious award for life-long service to African Studies. Such life-long career awards are a feature of many long established associations in individual disciplines, particularly in Europe where special medals are struck to honor the recipient. Many of these awards are named after outstanding scholars so that the distinction is a shared one between the recipient and the person after whom the award is named. Many of our leading Africanists never receive the Herskovits award and as a consequence are never honored for the work they do by our Association. A feature of many of our distinguished Africanists is their interdisciplinary breadth of vision and expertise, a valuable asset in an Africanist but not necessarily a credential to assure them adequate recognition in their parent discipline.

I should like to recommend to the Governing Board of the Association that an annual award be instituted whereby we recognize life-long achievement. The recipients would not necessarily have to be academics. Nominees could also include journalists, diplomats, economic advisers, scientists or anyone we might deem as a collective body to have made a significant contribution to the African cause and particularly to the promotion of African scholarship, education; to a greater understanding of Africa within the English-speaking world; or to the improvement of the quality of life, interpreted in its widest sense, in Africa. What I have in mind is something similar to the award scheme at one time initiated by the Haile Selassie Foundation which honored scholars of the ilk of Louis Leakey and Theodore Monod.

Nominations would be reviewed by a standing committee of the Association which would include on it a significant number of persons with at least 15 years experience in African studies. Assessors would also be invited from amongst our distinguished colleagues in Africa who could evaluate the impact and influence of the work of the nominees within Africa itself. In the first instance, whilst the endowment might be limited and administrative snags not ironed out, the award should be limited to scholars residing or working presently or for a significant part of their career in North America. Each recipient would be honored at a special dinner which would be held during the annual meeting of the Association and at which the Association would be informed of the achievements of the honoree who would then deliver a specially prepared address. The address and the introduction would be printed in either one of the Association's journals or preferably in a specially produced booklet. Carefully selected guests, including diplomats, key journalists and State Department employees would be invited to the dinner to add further honor to the occasion.

It would be appropriate to give a name to the award such as the Africa medal or it could be named after a deceased Africanist scholar of distinction such as W.B. Du Bois or anyone else who met the approbation of the Board. The award should consist of a specially struck medallion and ribbon (or some similar physical memento of intrinsic value) 